\title{
Pulmonary function, cholinergic bronchomotor tone, and cardiac autonomic abnormalities in type 2 diabetic patients
}

E. Melo, E.O. Vianna,

L. Gallo Jr., M.C. Foss and J. Terra-Filho
Departamento de Clínica Médica, Faculdade de Medicina de Ribeirão Preto, Universidade de São Paulo, Ribeirão Preto, SP, Brasil

\begin{abstract}
Correspondence
J. Terra-Filho

Departamento de Clínica Médica FMRP, USP

Av. Bandeirantes, 3900

14049-900 Ribeirão Preto, SP

Brasil

Fax: +55-16-633-6695

E-mail: jtfilho@fmrp.usp.br
\end{abstract}

Publication supported by FAPESP

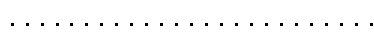

Received November 19, 2001

Accepted October 4, 2002
Abstract

This prospective study analyzed the involvement of the autonomic nervous system in pulmonary and cardiac function by evaluating cardiovascular reflex and its correlation with pulmonary function abnormalities of type 2 diabetic patients. Diabetic patients $(\mathrm{N}=17)$ and healthy subjects $(\mathrm{N}=17)$ were evaluated by 1$)$ pulmonary function tests including spirometry, He-dilution method, $\mathrm{N}_{2}$ washout test, and specific airway conductance (SGaw) determined by plethysmography before and after aerosol administration of atropine sulfate, and 2) autonomic cardiovascular activity by the passive tilting test and the magnitude of respiratory sinus arrhythmia (RSA). Basal heart rate was higher in the diabetic group $(87.8 \pm 11.2 \mathrm{bpm}$; mean $\pm \mathrm{SD})$ than in the control group $(72.9 \pm 7.8 \mathrm{bpm}$, $\mathrm{P}<0.05)$. The increase of heart rate at $5 \mathrm{~s}$ of tilting was $11.8 \pm 6.5 \mathrm{bpm}$ in diabetic patients and $17.6 \pm 6.2 \mathrm{bpm}$ in the control group $(\mathrm{P}<0.05)$. Systemic arterial pressure and RSA analysis did not reveal significant differences between groups. Diabetes intragroup analysis revealed two behaviors: 10 patients with close to normal findings and 7 with significant abnormalities in terms of RSA, with the latter subgroup presenting one or more abnormalities in other tests and clear evidence of cardiovascular autonomic dysfunction. End-expiratory flows were significantly lower in diabetic patients than in the control group $(\mathrm{P}<0.05)$. Pulmonary function tests before and after atropine administration demonstrated comparable responses by both groups. Type 2 diabetic patients have cardiac autonomic dysfunction that is not associated with bronchomotor tone alterations, probably reflecting a less severe impairment than that of type 1 diabetes mellitus. Yet, a reduction of end-expiratory flow was detected.

\section{Introduction}

Several respiratory alterations have been reported in association with diabetes mellitus, mainly insulin-dependent diabetes, including alveolar epithelial and capillary basal membrane thickening (1), reduction of diffusion capacity $(2,3)$, centrilobular emphysema (4),
Key words

- Diabetes mellitus

- Autonomic nervous system

- Autonomic neuropathy

- Heart rate variability

- Blood pressure variability 
manifestations of dysautonomy being more common in the cardiovascular, genitourinary, gastrointestinal, and thermoregulatory systems (10). In the non-insulin dependent, type 2, diabetic population, there is evidence that the expression of neural damage may be more complex due to overlapping hormonal, metabolic, and circulatory effects associated with old age (11). The autonomic neuropathy of diabetic patients may influence the control of breathing and this might explain the sudden deaths occurring in patients with severe disease (12). There is increasing evidence that the autonomic control of airway smooth muscle may also be altered in type 1 diabetes (13).

In a previous study from our laboratory, we showed that the parasympathetic regulation of airway caliber may be damaged in diabetes mellitus, characterizing a bronchomotor dysautonomy. However, at that time, only insulin-dependent patients were studied. In those cases, there was a correlation between bronchial dysautonomy and cardiac dysautonomy, the latter demonstrated by quantitative analysis of the reflex heart rate (HR) responses (14).

Since the time course and pathophysiology of type 2 diabetes may be different from that of the type 1 form of this disease, we performed a prospective study to analyze the involvement of the autonomic nervous system by evaluating cardiovascular reflex and its possible correlation with pulmonary function abnormalities of type 2 diabetic patients detected by spirometry, flow-volume curve, plethysmography, and the $\mathrm{N}_{2}$ washout test before and after cholinergic blockade. A quantitative study of autonomic cardiovascular activity was carried out on these subjects using the tilting test and the magnitude of respiratory sinus arrhythmia (RSA).

\section{Patients and Methods}

\section{Subjects}

In a case-control prospective protocol, we studied 17 type 2 diabetic patients aged
31 to 60 years and 17 healthy individuals aged 34 to 58 years chosen from the Ribeirão Preto general community as a normal control group. The male/female ratio was $8 / 9$ for both diabetic and control subjects. The inclusion criteria for the diabetic group were: non-insulin dependent diabetes mellitus for at least 2 years confirmed and treated at our hospital, a negative history of smoking, normal weight, and normal arterial pressure. Volunteers were taking medication only for diabetes. None of the patients or normal volunteers had a recent or remote history of cardiorespiratory disease or respiratory allergy and none had suffered an acute respiratory infection in the previous 3 months. Serologic tests for Chagas' disease (complement fixation and immunofluorescence) were negative in all individuals studied. All subjects gave informed consent to participate in this institutional Ethics Committee-approved protocol.

\section{Tilting test}

The head-up tilting test with an inclination of $70^{\circ}$ was performed with the aid of a tilting table that permitted rapid passive changes in body position without muscular effort on the part of the individual (15). HR was monitored by continuous ECG recording. Arterial pressure was measured with a sphygmomanometer during the basal period in the supine position and during the tilting test. After $30 \mathrm{~min}$ of rest in the supine position, normal and diabetic patients were submitted to rapid $70^{\circ}$ head-up tilting and were left in this position for $5 \mathrm{~min}$, when returning the table to the horizontal position terminated the test.

\section{Respiratory sinus arrhythmia test}

For determination of RSA magnitude, the individuals were taught to breathe deeply at a respiratory rate of 6 cycles $/ \mathrm{min}$. A pneumotachograph (Fleisch No. 2) was used to record flow that was electronically integrated for the 
measurement of tidal volume (Hewlett-Packard 4588B, Fort Collins, CO, USA). The instantaneous HR was obtained using a cardiotachometer that received the ECG signal from a $\mathrm{D}_{2}$ lead of the ECG channel. RSA magnitude is defined as the mean of the differences between maximum and minimum instantaneous HR values over six successive respiratory cycles. The RSA test is simple, noninvasive, and sensitive in detecting a cardiovascular autonomic neuropathy $(14,15)$.

\section{Pulmonary function tests}

Forced vital capacity (FVC), forced expiratory volume in the first second $\left(\mathrm{FEV}_{1}\right)$, forced expiratory flow from 25 to $75 \%$ of $\mathrm{FVC}\left(\mathrm{FEF}_{25-75 \%}\right)$, total lung capacity, residual volume, and functional residual capacity (FRC) were measured using a 9-liter spirometer (Collins Modular Lung Analyzer System, Braintree, MA, USA) and the helium dilution method. Instantaneous FEF (Vmax) measurements throughout the flow-volume curve were made with the aid of a pneumotachometer and the volume change was determined by integration of an electronic flow signal (Hewlett-Packard 47804S). All these pulmonary function tests met the American Thoracic Society criteria $(16,17)$. The best of three efforts in the measurements of FVC and $\mathrm{FEV}_{1}$ was selected $(16,18)$. Thoracic gas volume $\left(\mathrm{V}_{\mathrm{TG}}\right)$ and airway resistance (Raw) were measured by the methods of DuBois et al. $(19,20)$ using a constant-volume body plethysmograph (W.E. Collins 09001). Specific airway conductance (SGaw) was calculated by dividing the Raw reciprocal (i.e., $1 /$ Raw) by the $\mathrm{V}_{\mathrm{TG}}$ at which the measurements were made. For the Raw evaluation, at least ten measurements were made per individual during each phase of the study, and the results are reported as mean values.

\section{Atropine administration}

The changes in airway caliber induced by cholinergic blockade were inferred through the SGaw changes provoked by the aerosol administration of atropine sulfate at the concentration of $1 \mathrm{mg} / \mathrm{ml}$. The aerosol was generated by a nebulizer (De Vilbiss 645, Somerset, PA, USA) connected to a compressed air source with a flow of $8 \mathrm{l} / \mathrm{min}$. A hand-operated valve permitted nebulization to occur only during the inspiratory phase of the respiratory cycle. The aerosol was inhaled through the mouth during slow and deep inspirations initiated at FRC and lasting approximately $4 \mathrm{~s}$. In each case the nebulized volume was $1 \mathrm{ml}$, equivalent to $1 \mathrm{mg}$ of atropine sulfate, a sufficient dose to provoke bronchodilation in normal individuals (14, 21). The expiratory flows, $V_{T G}$, and Raw measurements were repeated $5 \mathrm{~min}$ after the end of nebulization.

\section{Nitrogen washout test}

The single-breath $\mathrm{N}_{2}$ washout test was performed using an automated apparatus for lung function evaluation (Hewlett-Packard 47804 S). The $\mathrm{N}_{2}$ concentration in the mouth was measured with a fast-response analyzer (Hewlett-Packard 47302A) connected to a pneumotachometer (Hewlett-Packard 47304A) that allowed the measurement of expiratory flow, and, by calculation, expiratory volume (x-axis) concomitantly to $\mathrm{N}_{2}$ concentration (y-axis). This curve was displayed on a screen for both the patient and the investigator. To evaluate closing volume and alveolar $\mathrm{N}_{2}$ slope $\left(\mathrm{S}_{\mathrm{III}}\right)$, the patients were asked to breathe in $100 \% \mathrm{O}_{2}$ from residual volume to total lung capacity. Then, during the expiration to residual volume, the flow was kept below $0.5 \mathrm{l} / \mathrm{s}$. The subjects performed at least two satisfactory trials (5 min apart) $(22,23)$.

\section{Statistical analysis}

Data were analyzed by the unpaired Student $t$-test for comparisons between groups. The proportion of males and females in each 
group was compared by the chi-square test.

Data are expressed as mean $\pm \mathrm{SD}$. A P value $<0.05$ was considered to be significant.

A descriptive statistical analysis was also done in order to calculate the number and percentage of diabetic patients that were outside the range of a prediction interval $(95 \%)$ of a " $\mathrm{t}$ " distribution with $\mathrm{n}-1$ degrees of freedom, i.e., mean $\pm \mathrm{t}_{(1-\propto / 2, n-1)} \times(\mathrm{s} / \sqrt{ } \mathrm{n})$ for the control group, where $\mathrm{s}=$ standard deviation of the sample data.

Table 1. Subject characteristics.

\begin{tabular}{lcc}
\hline & Diabetic group & Control group \\
\hline Number of subjects & 17 & 17 \\
Gender (male/female) & $8 / 9$ & $8 / 9$ \\
Age (years) & $47.0 \pm 7.0$ & $45.0 \pm 7.0$ \\
Weight $(\mathrm{kg})$ & $64.3 \pm 13.5$ & $72.5 \pm 10.7$ \\
Height $(\mathrm{cm})$ & $161.4 \pm 13.0$ & $165.4 \pm 8.4$ \\
Body surface $\left(\mathrm{m}^{2}\right)$ & $1.7 \pm 0.2$ & $1.8 \pm 0.1$ \\
Duration of diabetes (years) & $7.5 \pm 5.2$ & - \\
Peripheral neuropathy & 8 & 0 \\
Retinopathy & 5 & 0 \\
\hline
\end{tabular}

Data are reported as means \pm SD.

\section{Results}

Subject characteristics and clinical data are summarized in Tables 1 and 2. There were no differences in anthropometric parameters between the diabetic and control groups. The results obtained during the study of the autonomic cardiovascular activity showed that in the resting supine position, diabetic patients had significantly higher HR values $(87.8 \pm 11.2$ vs $72.9 \pm 7.8 \mathrm{bpm}$ for the control group, $\mathrm{P}<0.05$ ) (Figure 1 ). Moreover, in this group, seven subjects (40\%) had high HR values based on the range established by the prediction interval. Systemic arterial pressure at baseline was not statistically different. During the tilting test, the increase in $\mathrm{HR}$ at $5 \mathrm{~s}$ was significantly lower in the diabetic group $(11.8 \pm 6.5$ vs $17.6 \pm 6.2$ $\mathrm{bpm}$ for the control group, $\mathrm{P}<0.05)$. Two diabetic patients $(12 \%)$ were outside the normal prediction interval. No significant difference in HR increase was observed between controls and diabetic patients at $10 \mathrm{~s}$ or at other time points. Also, the variation of

\begin{tabular}{|c|c|c|c|c|c|c|c|c|c|c|}
\hline Patient & $\begin{array}{l}\text { Age } \\
\text { (years) }\end{array}$ & $\begin{array}{l}\text { Height } \\
(\mathrm{cm})\end{array}$ & $\begin{array}{l}\text { Weight } \\
(\mathrm{kg})\end{array}$ & $\begin{array}{l}\text { Fasting glycemia } \\
\text { (mg/100 ml) }\end{array}$ & $\begin{array}{l}\mathrm{HbA} 1 \\
(\%)\end{array}$ & $\begin{array}{l}\text { Cholesterol } \\
\text { (mg/100 ml) }\end{array}$ & $\begin{array}{l}\text { Triglycerides } \\
\text { (mg/100 ml) }\end{array}$ & $\begin{array}{l}\text { Serum creatinine } \\
\text { (mg/100 ml) }\end{array}$ & $\begin{array}{l}\text { Diagnosis } \\
\text { (years) }\end{array}$ & Retinopathy \\
\hline 1 & 40.0 & 151.0 & 44.0 & 118.0 & 6.7 & 288.0 & 157.0 & 1.0 & 4.0 & Yes \\
\hline 2 & 47.0 & 156.5 & 68.2 & 114.0 & 8.6 & 199.0 & 107.0 & 0.9 & 15.0 & Yes \\
\hline 3 & 48.0 & 162.0 & 56.3 & 145.0 & - & 310.0 & 153.0 & 1.2 & 13.0 & Yes \\
\hline 4 & 53.0 & 184.0 & 86.4 & 106.0 & 7.5 & 235.0 & 172.0 & 1.1 & 11.0 & No \\
\hline 5 & 55.0 & 150.0 & 49.5 & 99.0 & 6.4 & 157.0 & 48.0 & 0.9 & 2.0 & No \\
\hline 6 & 57.0 & 144.5 & 63.4 & 203.0 & 10.6 & 215.0 & 207.0 & 0.8 & 13.5 & No \\
\hline 7 & 60.0 & 144.0 & 52.4 & 113.0 & 8.0 & 218.0 & 199.0 & 1.0 & 11.0 & - \\
\hline 8 & 31.0 & 154.5 & 64.8 & 155.0 & 8.9 & 248.0 & 146.0 & 0.6 & 4.0 & No \\
\hline 9 & 36.0 & 158.5 & 66.8 & 142.0 & 7.9 & 153.0 & 162.0 & 0.8 & 12.0 & No \\
\hline 10 & 42.0 & 175.5 & 76.0 & 147.0 & 9.0 & 205.0 & 175.0 & 0.7 & 13.0 & Yes \\
\hline 11 & 44.0 & 167.0 & 67.2 & 164.0 & 8.8 & 192.0 & 162.0 & 1.0 & 11.0 & - \\
\hline 12 & 45.0 & 166.0 & 79.0 & 131.0 & 7.0 & 211.0 & 259.0 & 1.1 & 5.0 & No \\
\hline 13 & 47.0 & 148.0 & 50.5 & 135.0 & 6.9 & 173.0 & 188.0 & 0.7 & 15.0 & No \\
\hline 14 & 49.0 & 149.0 & 42.7 & 101.0 & 6.2 & 239.0 & 126.0 & 0.5 & 8.0 & Yes \\
\hline 15 & 49.0 & 170.0 & 72.8 & 155.0 & - & 141.0 & 247.0 & 1.3 & 11.0 & No \\
\hline 16 & 52.0 & 175.5 & 67.5 & 140.0 & 8.6 & 193.0 & 82.0 & 0.8 & 5.0 & Yes \\
\hline 17 & 50.0 & 180.0 & 85.6 & 121.0 & 5.8 & 236.0 & 17.0 & 0.7 & 4.0 & - \\
\hline Mean & 47.4 & 160.9 & 64.3 & 134.6 & 7.8 & 212.5 & 153.4 & 0.9 & 9.3 & \\
\hline SD & 7.4 & 12.8 & 13.5 & 26.6 & 1.3 & 45.1 & 63.6 & 0.2 & 4.4 & \\
\hline
\end{tabular}


arterial pressure was comparable in both groups, except for one diabetic patient that interrupted the test before the fifth minute due to symptomatic hypotension.

The magnitude of RSA was not significantly different in the diabetic group; the mean values were 16.8 and $19.3 \mathrm{bpm}$ for the diabetic and control groups, respectively. A diabetes intragroup analysis revealed two behaviors: 10 patients with close to normal findings and 7 individuals with significant abnormalities in terms of RSA, with the latter subgroup also presenting one or more abnormalities in other tests and clear evidence of cardiovascular autonomic dysfunction. These patients formed the autonomic cardiovascular denervated group that was compared with the other subgroup of diabetic patients, i.e., the non-denervated diabetic group (Figures 1 and 2).

The data of the pulmonary function tests are presented in Table 3. Diabetic patients and control subjects had similar values except for the measurement of flow rates generally related to the peripheral airways $\left(\mathrm{FEF}_{25-75 \%}, \mathrm{Vmax}_{50 \%}\right.$ and $\left.\mathrm{Vmax}_{75 \%}\right)$ that were significantly lower in the diabetic group
$(\mathrm{P}<0.05)$. The non-denervated group did not differ from the denervated diabetic group. The evaluation of $\mathrm{V}_{\mathrm{TG}}$, Raw, and SGaw revealed equivalent results in the diabetic and control groups. SGaw results are shown in Figure 3; both pre- and post-atropine admin-

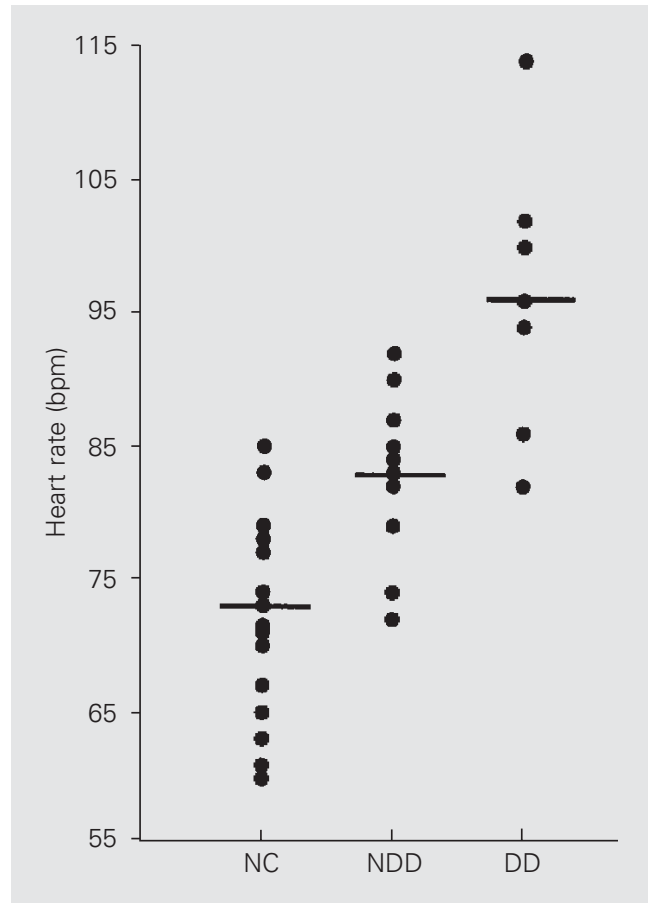

Figure 1. Basal heart rate of type 2 diabetic patients $(\mathrm{DD}=$ denervated diabetic group, $\mathrm{N}=7$; NDD $=$ non-denervated diabetic group, $\mathrm{N}=10$ ), and normal controls ( $N C ; N=17$ ). Horizontal bars indicate means. $\mathrm{P}<0.05$, DD vs NC (unpaired Student $t$ test).

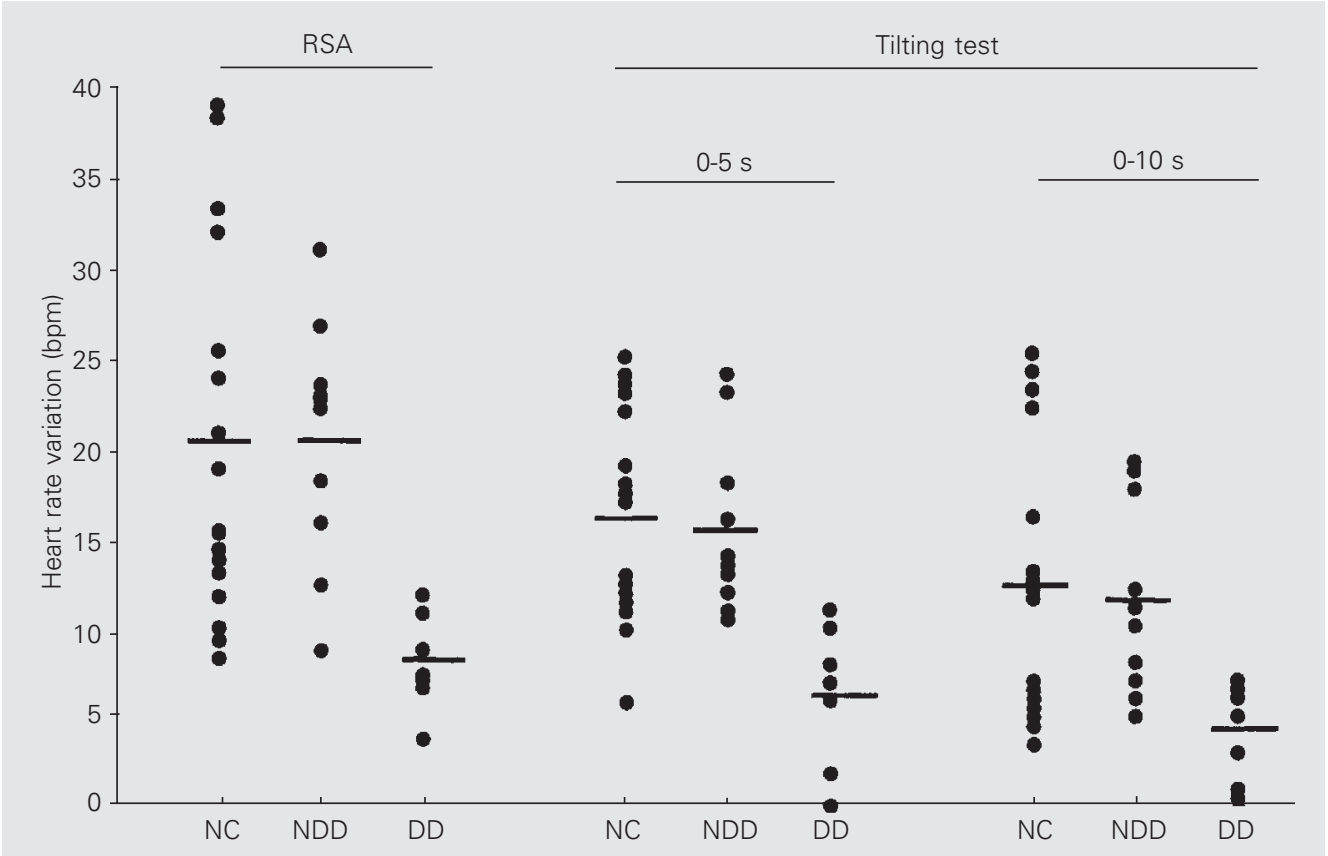

Figure 2. Heart rate variation during the tilting test and respiratory sinus arrhythmia (RSA) in type 2 diabetic patients $(\mathrm{DD}=$ denervated diabetic group, $\mathrm{N}=$ 7; NDD = non-denervated diabetic group, $N=10$ ) and normal controls ( $N C ; N=17$ ). Horizontal bars indicate means. $P<0.05$ DD vs NC (unpaired Student ttest). 
istration values were similar for the control and the diabetic group, even when comparing the non-denervated with the denervated

Table 3. Pulmonary function tests.

\begin{tabular}{lcc}
\hline Parameter & Diabetic group & Control group \\
\hline Vital capacity (liters) & $3.4 \pm 1.0$ & $3.9 \pm 0.8$ \\
FRC (liters) & $2.6 \pm 0.9$ & $2.8 \pm 0.6$ \\
Residual volume (liters) & $1.6 \pm 0.5$ & $1.9 \pm 0.5$ \\
Total lung capacity (liters) & $5.0 \pm 1.2$ & $5.7 \pm 1.1$ \\
FVC (liters) & $3.5 \pm 0.9$ & $3.9 \pm 0.8$ \\
$\mathrm{FEV}_{1}$ (liters) & $2.8 \pm 0.6$ & $3.1 \pm 0.6$ \\
$\mathrm{FEV}_{1} / \mathrm{FVC}$ (\%) & $80.9 \pm 6.2$ & $81.1 \pm 7.2$ \\
$\mathrm{FEF}_{25-75 \%}$ (liter/s) & $2.9 \pm 1.0$ & $3.5 \pm 1.2^{*}$ \\
Vmax $_{50 \%}$ (liter/s) & $3.4 \pm 1.1$ & $4.3 \pm 1.2^{*}$ \\
Vmax $_{75 \%}$ (liter/s) & $1.0 \pm 0.5$ & $1.5 \pm 0.6^{*}$ \\
$\mathrm{SGaw}_{\mathrm{cm}} \mathrm{H}_{2} \mathrm{O}^{-1} \mathrm{~s}^{-1}$ ) & $0.24 \pm 0.06$ & $0.23 \pm 0.08$ \\
$\mathrm{~V}_{\mathrm{TG}}$ (liters) & $2.6 \pm 0.7$ & $2.7 \pm 0.7$ \\
$\mathrm{~S}_{\text {III }}$ (\% $\mathrm{N}_{2} /$ liter) & $1.5 \pm 0.8$ & $0.9 \pm 0.5$ \\
\hline
\end{tabular}

Data are reported as means \pm SD.

${ }^{*} \mathrm{P}<0.05$ compared to the diabetic group (unpaired Student $t$-test).

$F R C=$ functional residual capacity, FVC $=$ forced vital capacity, FEV ${ }_{1}=$ forced expiratory volume in the first second, $\mathrm{FEF}_{25-75 \%}=$ forced expiratory flow from 25 to $75 \%$ of $\mathrm{FVC}, V_{\max }=$ instantaneous forced expiratory flow, $S \mathrm{Saw}=$ specific airway conductance, $\mathrm{V}_{\mathrm{TG}}=$ thoracic gas volume, $\mathrm{S}_{\mathrm{III}}=$ alveolar $\mathrm{N}_{2}$ slope.

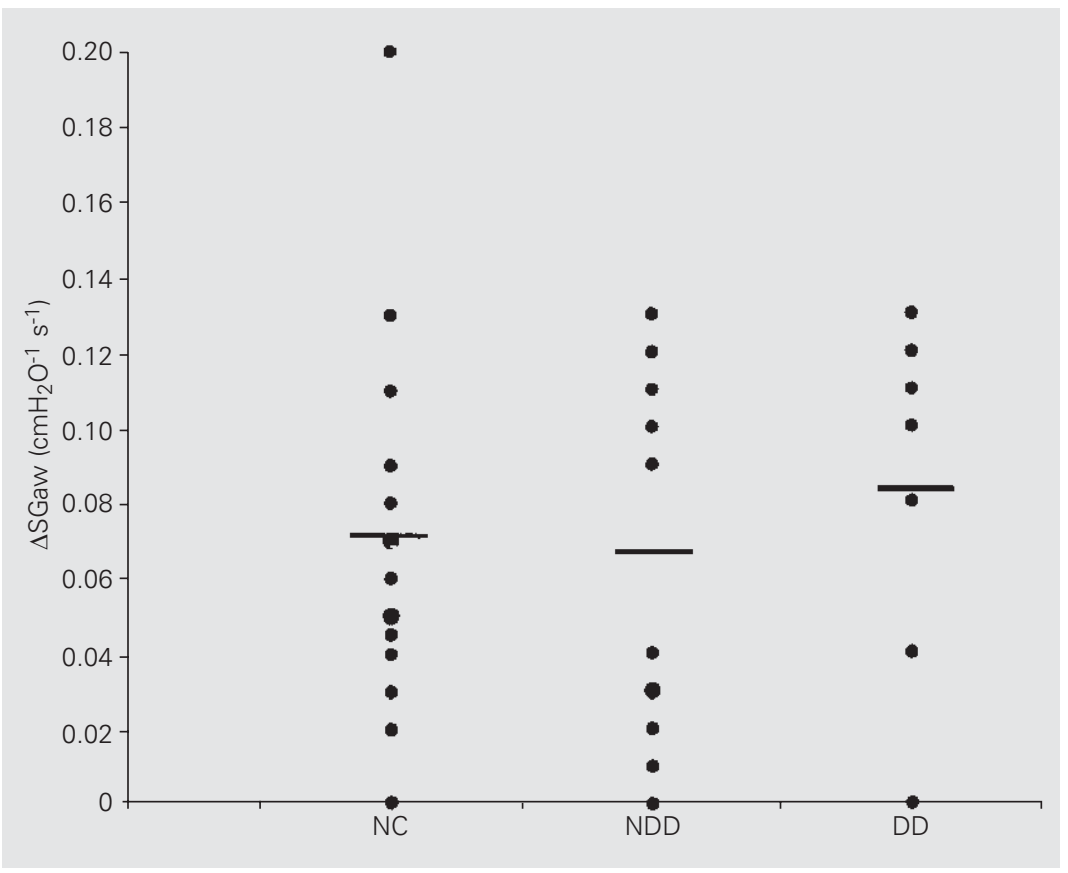

Figure 3. Changes in specific airway conductance (SGaw) from pre- to post-atropine administration measurements in type 2 diabetic patients $(D D=$ denervated diabetic group, $N=7$; NDD = non-denervated diabetic group, $N=10$ ) and normal controls ( $N C ; N=17$ ). Horizontal bars indicate means. group. The changes of lung function obtained with atropine administration were not different between groups (Figure 3).

The $\mathrm{N}_{2}$ washout test demonstrated comparable measurements for the two groups. The results for $\mathrm{S}_{\mathrm{III}}$ were $0.9 \pm 0.5$ and $1.5 \pm$ $0.8 \% \mathrm{~N}_{2} / 1$ for the control and diabetic group, respectively, and the results for closing volume ( $\%$ of the vital capacity) were $22.1 \pm 8.6$ and $23.1 \pm 6.1 \%$. However, according to the definition of normal values by Buist and Ross (23), the diabetic group had 7 subjects with higher than normal values of $\mathrm{S}_{\mathrm{III}}$.

\section{Discussion}

This study has demonstrated that patients with type 2 diabetes mellitus have evidence of depression of the parasympathetic autonomic control of the heart, as judged by the higher HR observed under basal conditions in the supine position and the depressed response of the RSA. However, our results do not suggest that this alteration is accompanied by dysfunction of the parasympathetic regulation of airway caliber. The response of the diabetic group to inhaled atropine did not differ from that observed in the control group.

A decline in the reflex autonomic control of HR with age has been reported previously in a healthy population $(24,25)$. Smoking has also been reported to reduce vagal tone (26). However, in this study there were no significant differences between groups in age, smoking status, or male/female distribution. In Chagas' disease, which is endemic in some South American countries, damage to the intracardiac parasympathetic ganglion cells also provokes intense depression of the vagal regulation of the heart $(27,28)$. Nevertheless, the negative results of specific serologic tests obtained for the present subjects permitted us to exclude the concomitant presence of Chagas' heart disease. Thus, the present data indicate that diabetes mellitus is the only disease responsible for 
the findings described. In addition, previous studies from our laboratory have shown similar results for insulin-dependent diabetic patients (14), and several other investigators have linked diabetes mellitus to autonomic dysfunction (29-31). The diabetic patients studied had particular characteristics in that they were middle-aged, normotensive, nonsmokers, and probably not typical of the "average" patient with type 2 diabetes who might have demonstrated more changes. Nevertheless, the study group had an apparent cardiac parasympathetic neuropathy, which would place them at higher risk of sudden cardiac death.

Analysis of the time course of HR variation during the tilting test in normal individuals demonstrated that, while the initial tachycardia depends on suppression of vagal tone, the maintenance of an elevated HR during the equilibration period after $5 \mathrm{~s}$ in the tilted position is related to sympathetic stimulation $(15,27)$. These results show that at the fifth minute of the tilting test (i.e., during the equilibrium phase), the mean increase in HR in the two groups did not differ. On this basis, the results suggest that even in the patients with dysfunction of the parasympathetic control of the heart (diabetic group), there was sufficient sympathetic activity to maintain a normal HR increase during the equilibrium phase of passive tilting. Furthermore, the maintenance of normal arterial pressure levels during the tilting test indicates the preservation of the sympathetic efferent control of peripheral vascular resistance.

Aerosol administration of atropine sulfate was accompanied by an increase in SGaw in both groups, indicating that basal parasympathetic activity on the airways was present in diabetic patients in a proportion similar to that observed in healthy subjects. The comparative analysis between non-denervated and denervated diabetic subgroups showed no differences, dissociating respiratory changes from cardiac dysautonomy in this small population. In insulin-dependent diabetes mellitus, however, the bronchodilatation produced by inhaled atropine has been reported to be lower in patients with symptoms of autonomic neuropathy and depressed HR responses to autonomic tests (14). The reasons for a similar bronchomotor response of the control and diabetic groups in our study may be explained by lower severity of the local autonomic dysfunction and or metabolic characteristics of type 2 disease. The diabetic group had a less severe cardiac dysautonomy as compared to that previously reported for insulin-dependent patients (14).

The lung volumes and capacities were not reduced in the diabetic group when compared to the control group, even with the results normalized in terms of predicted values. The changes in these parameters reported for insulin-dependent young diabetic patients have been explained on the basis of changes in the distension property of the binomial lungs/thorax $(7,8,32)$ or of changes in the strength of respiratory muscles due in part to the peripheral neuropathy. Normal values of these parameters are compatible with relative preservation or only mild impairment.

During the basal period before the administration of atropine, the maximal expiratory flows or derivable values of the diabetic group in lung volumes close to the total lung capacity did not show any significant difference compared to the control group data. This finding is compatible with the absence of changes in large airway resistance. This was corroborated functionally by normal values of Raw and SGaw in the diabetic group and reinforced the relative preservation of respiratory muscle function since the determinants of these flows are resistance of large airways and muscle effort $(33,34)$.

However, for lung volumes lower than approximately $50 \%$ FVC, a significant reduction of the expiratory flows - $\mathrm{FEF}_{25-75 \% \text {, }}$ $\operatorname{Vmax}_{50 \%}$, and $\operatorname{Vmax}_{75 \%}$ - was observed in 
the diabetic group as compared to the control group. Moreover, independently of the diabetic subgroup (non-denervated or denervated), more than $50 \%$ of the patients presented end-expiratory flows below the normal values established in the literature (35). Although we have not found a clear consensus in the literature regarding the functional meaning of the isolated end-expiratory flow reduction, classic physiologic studies involving the lung static recoil, the increase in airway resistance in the upstream segment from the alveoli to the equal pressure point, and the phenomenon of dynamic airway compression permit us to suggest their association with abnormalities in elastic recoil forces and peripheral airways. Thus, in spite of the evidence that in normal individuals the small airways barely contribute to total resistance, in the presence of obstruction their contribution to total airway resistance may increase significantly and we believe this may be detected through regular forced expiratory maneuvers. In this case, the lung static recoil and the resistance of small airways can be considered important elements in determining the intensity of these flows $(34,36)$ and both can be modified by several physiological factors such as metabolic lung involve- ment by diabetes, especially related to the elastic matrix (8), peripheral airway diseases, and abnormal vagal activity. The change in bronchomotor tone that can result from denervation may cause a variable change/reduction of lung elastic recoil, the propelling power of the flow, associated with different degrees of airway resistance variation in spite of the bronchodilator effect (37). Our results concerning the action of the anticholinergic drug are not compatible, by themselves, with the presence of detectable parasympathetic airway denervation. Airway structural changes were possibly indicated on the basis of the flow decrease detected, as corroborated by data from the $\mathrm{N}_{2}$ washout test, which showed slightly higher $\mathrm{S}_{\mathrm{III}}$ values in the diabetic group. In spite of the observed atropine response, it cannot be ruled out that part of these alterations are a consequence of some degree of denervation.

In conclusion, it was possible to demonstrate in a subgroup of type 2 diabetic patients evidence of autonomic dysfunction, mainly restricted to the parasympathetic system, which was not associated with bronchomotor tone alterations. Yet, a small airway dysfunction was detected in the same diabetic patients.

\section{References}

1. Vracko RD, Thorning D \& Huang TW (1979). Basal lamina of alveolar epithelium and capillaries: quantitative changes with aging and in diabetes mellitus. American Review of Respiratory Disease, 120: 973-983.

2. Fuso L, Cotroneo P, Basso S, DeRosa M, Manto A, Ghirlanda G \& Pistelli R (1996). Postural variations of pulmonary diffusing capacity in insulin-dependent diabetes mellitus. Chest, 110: 1009-1013.

3. Ljubic S, Metelko Z, Car N, Roglic C \& Drazic Z (1998). Reduction of diffusion capacity for carbon monoxide in diabetic patients. Chest, 114: 1033-1035

4. Kodolova IM, Lysenko LV \& Saltykov BB (1982). Changes in the lungs in diabetes mellitus. Arkhiv Patologii, 44: 35-40.

5. Madia AM, Rozovski SJ \& Kagan HM (1979). Changes in lung lysyl oxidase activity in streptozotocin-diabetes and in starvation. Biochimica et Biophysica Acta, 585: 481-487.

6. Wanke T, Formanek D, Auinger M, Popp W, Zwick H \& Irsigler K (1991). Inspiratory muscle performance and pulmonary function changes in insulin-dependent diabetes mellitus. American Review of Respiratory Disease, 143: 97-100.

7. Schnapf BM, Banks RA, Silverstein JH, Rosenbloom AL, Chesrown SE \& Laughlin GM (1984). Pulmonary function in insulin-dependent diabetes mellitus with limited joint mobility. American Review of Respiratory Disease, 130: 930-932.

8. Schuyler MR, Niewoehner DE, Inkley SR \& Kohn R (1976). Abnormal lung elasticity in juvenile diabetes mellitus. American Review of Respiratory Disease, 113: 37-41.

9. Sandler M, Bunn AE \& Stewart RI (1987). Cross-section study of pulmonary function in patients with insulin-dependent diabetes mellitus. American Review of Respiratory Disease, 135: 223-229.

10. Kennedy WR, Navarro X, Sakuta M, Mandell H, Knox CK \& Sutherland DE (1989). Physiological and clinical correlates of cardiorespiratory reflexes in diabetes mellitus. Diabetes Care, 12: 399408.

11. Sima AAF, Nathaniel V, Bril V, McEwen TAJ \& Greene DA (1988). 
Histopathological heterogeneity of neuropathy in insulin-dependent and non-insulin-dependent diabetes, and demonstration of axo-glial dysjunction in human diabetic neuropathy. Journal of Clinical Investigation, 81: 349-364.

12. Tantucci C, Scionti L, Bottini P, Dottorini ML, Puxeddu E, Casucci G \& Sorbini CA (1997). Influence of autonomic neuropathy of different severities on the hypercapnic drive to breathing in diabetic patients. Chest, 112: 145-153.

13. Douglas NJ, Campbell IW, Ewing DJ, Clark BF \& Flenley DC (1981). Reduced airway vagal tone in diabetic patients with autonomic neuropathy. Clinical Science, 61: 581-584.

14. Fonseca CMCS, Manço JC, Gallo Jr L, Barreira AA \& Foss MC (1992). Cholinergic bronchomotor tone and airway caliber in insulin dependent diabetes mellitus. Chest, 101: 1038-1043.

15. Marin-Neto JA, Gallo Jr L, Manço JC, Rassi A \& Amorim DS (1975). Postural reflexes in chronic Chagas' heart disease: heart rate and arterial pressure responses. Cardiology, 60: 343-357.

16. American Thoracic Society (1987). Standardization of spirometry. Statement of the American Thoracic Society. American Review of Respiratory Disease, 136: 1285-1307.

17. Crapo RO, Morris RH \& Gardner RM (1981). Reference spirometric values using techniques and equipment that meet at recommendation. American Review of Respiratory Disease, 123: 659-664.

18. Sorensen JB, Morris AH, Crapo RO \& Gardner RM (1980). Selection of the best spirometric values for interpretation. American Review of Respiratory Disease, 122: 802-805.

19. DuBois AB, Botelho SY \& Bedell GN (1956). A rapid plethysmographic method for measuring thoracic gas volume: a comparison with a nitrogen washout method for measuring functional residual capacity in normal subjects. Journal of Clinical Investigation, 35: 322-326

20. DuBois AB, Botelho SY \& Comroe Jr JH (1956). A new method for measuring airway resistance in man using a body plethysmograph: values in normal subjects and in patients with respiratory disease. Journal of Clinical Investigation, 35: 327-335.

21. Manco JC, Hyatt RE \& Rodarte JR (1987). Respiratory impedance in normal humans: effects of bronchodilatation and bronchoconstriction. Mayo Clinic Proceedings, 62: 487-497.

22. Rodarte JR, Hyatt RE, Rehder K \& Marsh HM (1977). New tests for the detection of obstructive pulmonary disease. Chest, 72: 762-768.

23. Buist AS \& Ross BB (1973). Quantitative analysis of the alveolar plateau in the diagnosis of early airway obstruction. American Review of Respiratory Disease, 108: 1078-1087.

24. O'Brien IAD, O'Hare P \& Corrall RJM (1986). Heart rate variability in healthy subjects: effect of age and the derivation of normal ranges for tests of autonomic function. British Heart Journal, 55: 348-354.

25. Amorim DS, Marin-Neto JA, Maciel BC, Gallo Jr L, Terra-Filho J \& Manço JC (1988). Cardiac autonomic function in healthy elderly people. Geriatric Cardiovascular Medicine, 1: 65-71.

26. Molgaard H, Hermansen K \& Bjerregaard P (1994). Spectral components of short-term RR interval variability in healthy subjects and effects of risk factors. European Heart Journal, 15: 1174-1183.

27. Marin-Neto JA, Gallo Jr L, Manço JC, Rassi A \& Amorim DS (1980). Mechanisms of tachycardia on standing: studies in normal individuals and in chronic Chagas' heart patients. Cardiovascular Research, 14: 541-550.

28. Gallo Jr L, Marin-Neto JA, Manço JC, Rassi A \& Amorim DS (1975) Abnormal heart rate responses during exercise in patients with Chagas' disease. Cardiology, 60: 147-162.

29. Wheeler T \& Watkins PJ (1973). Cardiac denervation in diabetes. British Medical Journal, 4: 584-586.

30. Ewing DJ, Campbell IW \& Clarke BF (1980). The natural history of diabetic autonomic neuropathy. Quarterly Journal of Medicine, 49: 95-108.

31. Pfeifer MA, Cook D, Brodsky J, Tice D, Reenan A, Swedine S, Halter JB \& Porte Jr D (1982). Quantitative evaluation of cardiac parasympathetic activity in normal and diabetic man. Diabetes, 31: 339-345.

32. Bell D, Collier A \& Matthews DM (1988). Are reduced lung volume in IDDM due to defect in connective tissue? Diabetes, 37: 829-831.

33. Ingran RH, McFadden ER, Wellman JJ \& Mead J (1977). Relative contribution of large and small airway to flow limitation in normal subjects before and after atropine and isoproterenol. Journal of Clinical Investigation, 59: 696-703.

34. Fry DL \& Hyatt RE (1960). Pulmonary mechanics: a unified analysis of the relationship between pressure, volume and gas flow in the lung of normal and diseased human subjects. American Journal of Medicine, 29: 672-689.

35. Knudson RJ, Slatin RC, Lebowitz MD \& Burrows B (1971). The maximal expiratory flow-volume curve. Normal standards, variability, and effects of age. American Review of Respiratory Disease, 113 587-600.

36. Mead J, Turner JM, Macklem PT \& Little JB (1967). Significance of the relationship between lung recoil and maximum expiratory flow. Journal of Applied Physiology, 22: 95-108.

37. Terra-Filho J, Gallo Jr L, Marin-Neto JA, Amorim DS, Maciel BC \& Manco Jr L (1987). Effects of atropine on lung mechanics. Respiration Physiology, 70: 265-274. 